Article

\title{
Specific Desulfuromonas Strains Can Determine Startup Times of Microbial Fuel Cells
}

\author{
Keren Yanuka-Golub ${ }^{1, *(\mathbb{D})}$, Leah Reshef ${ }^{2}$, Judith Rishpon ${ }^{1,2}$ and Uri Gophna ${ }^{1,2}$ \\ 1 The Porter School of Environmental Studies, Tel Aviv University, P.O. Box 39040, Tel Aviv 6997801, Israel; \\ JudithRi@tauex.tau.ac.il (J.R.); urigo@tauex.tau.ac.il (U.G.) \\ 2 The Shmunis School of Biomedicine and Cancer Research, Faculty of Life Sciences, Tel Aviv University, \\ Tel Aviv 6997801, Israel; leahfa@gmail.com \\ * Correspondence: keren.yanuka-golub@weizmann.ac.il
}

Received: 31 October 2020; Accepted: 27 November 2020; Published: 30 November 2020

\begin{abstract}
Microbial fuel cells (MFCs) can generate electricity simultaneously with wastewater treatment. For MFCs to be considered a cost-effective treatment technology, they should quickly re-establish a stable electroactive microbial community in the case of system failure. In order to shorten startup times, temporal studies of anodic biofilm development are required, however, frequent sampling can reduce the functionality of the system due to electroactive biomass loss; therefore, on-line monitoring of the microbial community without interfering with the system's stability is essential. Although all anodic biofilms were composed of Desulfuromonadaceae, MFCs differed in startup times. Generally, a Desulfuromonadaceae-dominated biofilm was associated with faster startup MFCs. A positive PCR product of a specific 16S rRNA gene PCR primer set for detecting the acetate-oxidizing, Eticyclidine (PCE)-dechlorinating Desulfuromonas group was associated with efficient MFCs in our samples. Therefore, this observation could serve as a biomarker for monitoring the formation of an efficient anodic biofilm. Additionally, we successfully enriched an electroactive consortium from an active anode, also resulting in a positive amplification of the specific primer set. Direct application of this enrichment to a clean MFC anode showed a substantial reduction of startup times from 18 to 3 days.
\end{abstract}

Keywords: microbial fuel cells (MFCs); startup time; Desulfuromonadaceae; anodic biofilm; specific 16S-Desulfuromonas primer set

\section{Introduction}

Microbial fuel cells (MFCs) are electrochemical devices that utilize anaerobic electroactive microorganisms to promote generation of electricity as a renewable clean source of energy directly from wastewater, and recently, for bioremediation of contaminated sites [1,2]. The working principle of MFCs is based on the activity of an electrochemically active biofilm that anaerobically oxidizes various organic substrates on the anode surface. The microorganisms that grow on the anode and that are responsible for the electron transfer are usually dissimilatory metal-reducing bacteria that are found ubiquitously in soils due to their ability to reduce insoluble elements, such as iron $\mathrm{Fe}^{+3}$ and manganese $\mathrm{Mn}^{+4}$ oxides [3]. The two best characterized families of dissimilatory metal reducing microorganisms in MFC systems are Geobacteracaea and Shewanellacaea. They differ considerably in metabolic flexibility [4] and in their individual electron transfer mechanisms [5]. Additional species belonging to the Desulfuromonadaceae family are well recognized, yet less studied metal reducers. Desulfuromonas members reduce elemental sulfur to sulfide in order to obtain energy, but can also use fumarate, ferric iron $\left(\mathrm{Fe}^{+3}\right)$, or manganese $\left(\mathrm{Mn}^{+4}\right)$ as terminal electron acceptors [6]. Moreover, they can obtain energy from the complete oxidation of organic compounds to carbon dioxide, while reducing 
extracellular electron acceptors [7]. Therefore, it is not surprising that Desulfuromonas and Geobacter species are so closely related [8] and are often reported to be the most predominate taxa found on MFC anodes. Anodic biofilms may face different, often suboptimal and varying abiotic conditions during their formation and operation, which is a challenge for the operation of MFCs as a cost-effective wastewater treatment technology. Of particular concern is the necessity of real-world MFCs to operate incessantly, as a wastewater plant cannot be shut down in the case of MFC failure. Thus, there is a true need for ways to monitor MFC operation in real time to predict system failure, as well as a means to rapidly restart the system, should such failure occur.

Major factors that can limit the electrical output in scaled-up MFCs are directly related to the electroactive microbial community, as well as its electron transport efficiency towards the anode. The anodic biofilm microbial composition has been considered to be a vital component of the MFC performance, and an important parameter for assessing the performance of MFCs and the metabolic processes taking place under different conditions [9-15]. Anodic biofilm enrichment involves specific selection processes that eventually dictate the biofilm community composition at steady state, i.e., when a stable maximal voltage has been obtained. Little is known about the microbial processes that actually stimulate the complex development of an anodic biofilm composition and function. Furthermore, anodic biofilms are often inappropriately considered to have reached the mature phase when a stable voltage output is first obtained, while the microbial community may still be changing at that time [16]. However, achieving this knowledge is difficult given typical MFCs experimental designs that allow anodic biofilm sampling only for limited time points during an experiment, which does not provide a direct linkage between the colonization process of microbial cells and power production. This is because sampling methods usually require sampling a considerable fraction of the biomass which necessitates mechanical disruption of the anode. We recently observed that efficient MFCs had Desulforomodaceae-dominated biofilms, while non-efficient MFCs showed a co-dominance of the anodic biofilm by both Desulfuromonadaceae and Geobacteraceae [17]. These findings led to a better understanding of the important community dynamics that occur during the inoculation phase, and eventually lead to either an efficient or non-efficient MFC. One of the important findings was that members of Desulfuromonadaceae were associated with efficient MFCs, and this association was accelerated when Geabacteraceae members were outcompeted from the MFC by the former group. Thus, there seemed to be strong competitive interactions between Desulfuromonadaceae and Geabacteraceae that strongly affected the startup efficiency of an MFC. Since there were no higher resolution taxonomic assignments of the family Desulfuromonadaceae to genus or species, it was unclear whether there were different species or strains of this family arising in the anodic biofilm at different time points and whether a specific strain within this family group was more strongly associated with MFC efficiency than others. Here, our aim was to detect specific patterns of microbial dynamics that characterize shorter MFC startup times, focusing on Desulfuromonadaceae strains using a specific Desulfuromonas-targeted PCR primer set. Furthermore, direct application of a Desulfuromonas-enriched consortium was attempted in order to substantially reduce startup times relative to those observed by inoculating MFCs with a wastewater sample alone.

\section{Materials and Methods}

\subsection{MFC Setup and Experimental Design}

Single-chamber, air-cathode MFCs were used for the enrichment of anodic respiring bacteria and suspended-cells (plankton) communities. The MFC was a bottle-type reactor (Adams \& Chittenden Scientific Glass Ltd., Berkeley, Canada), $160 \mathrm{~mL}$ in capacity, with anode electrodes made of carbon felt with a surface area of $32.64 \mathrm{~cm}^{2}$ (providing a specific surface area of $20 \mathrm{~m}^{2} \mathrm{~m}^{-3}$ ).

In every MFC reactor, two identical pieces of carbon felt were attached together and suspended at the center of the bottle. An air cathode was placed at the side port (circular), providing a specific surface area of $8 \mathrm{~m}^{2} \mathrm{~m}^{-3}$ (manganese-based catalyzed carbon commercial E4A electrode with a polypropylene 
microporous separator, Electric Fuel Ltd., Bet Shemesh, Israel). The anode and cathode of all close circuit MFCs were connected by Ti wires and an external resistor $(1000 \Omega)$. Voltage across the resistor was monitored at $5 \mathrm{~min}$ intervals using a computerized data acquisition system connected to a PC. Before the experiment began, all MFC bottles were thoroughly washed with diluted hydrochloric acid and ultrapure water (Milli-Q system, Millipore, Merck, Rosh-Ha'ayin, Israel), and then autoclaved for $30 \mathrm{~min}$ at $121^{\circ} \mathrm{C}$. The carbon felt anodes were immersed in $100 \%$ ethanol (Merck, Israel) overnight and rinsed with ultrapure water before being placed into the reactor.

In this study, four experiments were conducted similarly in terms of all parameters indicated above. Out of the four, three replicate experimental sets (named 2015, 2016, and 2016-2) were inoculated similarly using a diluted wastewater sample $(10 \% \mathrm{v} / \mathrm{v}$ of total reactor volume) as the microbial source. For experiment 2015, a sample was taken in March 2015. For experiment 2016, a sample was taken in February 2016, and finally for 2016-2, a wastewater sample was taken in September 2016. The fourth experimental set (2016-E) aimed to directly apply an enriched electroactive consortium (composed of $>50 \%$ Desulfuromonas spp.) from an active-operating MFC. The consortium was directly applied onto a clean anode in an MFC inoculated with a wastewater sample.

\subsection{MFC Operation}

The MFCs operated in batch-fed mode using bicarbonate buffered medium ( $30 \mathrm{mM}$ BCM). Each batch of BCM was prepared and immediately sterilized by filtration $(0.2 \mu \mathrm{m}$, Millipore, Merck, Rosh-Ha'ayin, Israel). The BCM medium contained a base composition of the following (per L): $2.5 \mathrm{~g} \mathrm{NaHCO}_{3}, 0.25 \mathrm{~g} \mathrm{NH}_{4} \mathrm{Cl}, 0.1 \mathrm{~g} \mathrm{MgCl}_{2} \cdot 6 \mathrm{H}_{2} \mathrm{O}$, and $0.1 \mathrm{~g} \mathrm{KCl}$. In addition, $5 \mathrm{~mL} \mathrm{~L}^{-1}$ of a vitamin mix (modified ATCC ${ }^{\circledR}$ Vitamin Supplement) and $1 \mathrm{~mL} \mathrm{~L}^{-1}$ of trace elements were added, containing the following (final concentration in $\mathrm{mg} \mathrm{L}^{-1}$ ): $\mathrm{FeSO}_{4} \cdot 7 \mathrm{H}_{2} \mathrm{O} 6.25, \mathrm{ZnCl}_{2} 0.4375, \mathrm{MnCl}_{2} \cdot 4 \mathrm{H}_{2} \mathrm{O}$ $0.625, \mathrm{H}_{3} \mathrm{BO}_{3} 0.0375, \mathrm{CaCl}_{2} \cdot 6 \mathrm{H}_{2} \mathrm{O} 0.8125, \mathrm{CuCl}_{2} \cdot 2 \mathrm{H}_{2} \mathrm{O} 0.0125, \mathrm{NiCl}_{2} \cdot 6 \mathrm{H}_{2} \mathrm{O} 0.15, \mathrm{Na}_{2} \mathrm{Mo}_{4} \cdot 2 \mathrm{H}_{2} \mathrm{O} 0.225$, and $\mathrm{CoCl}_{2} \cdot 6 \mathrm{H}_{2} \mathrm{O} 1.4875$ [18]. Acetate $(20 \mathrm{mM})$ was used as the carbon source.

\subsection{Bacterial Community Analysis}

Anodic biofilms and planktonic cells from the MFC systems were sampled at different time points for community and phylogenetic analysis, as previously described [17]. Briefly, total DNA was extracted from anodic biofilms or from the suspended cells using a PowerSoil DNA isolation kit (MO BIO Laboratories, Carlsbad, CA, USA), according to the manufacturer's instructions. For anode sampling, using a metal hollow cylindrical tube, four identical samples were cut out of the carbon felt $\left(0.2 \mathrm{~cm}\right.$ depth each disk) and placed directly into the Power Soil ${ }^{\circledR}$ bead tube for further extraction, according to the manufacturer's instructions. For cell suspension, $1300 \mu \mathrm{L}$ were sampled from the MFC bulk liquid after gentle mixing, then, centrifuged for $5 \mathrm{~min}(10,000 \mathrm{rpm})$, and then the supernatant was removed and the pellet was placed directly into the Power Soil ${ }^{\circledR}$ bead tube for further extraction. PCR amplification, 16S rRNA gene amplicon sequencing, and bioinformatics analysis were then performed as detailed in Supplementary Methods. Amplification was verified by electrophoresis on a $1 \%$ agarose gel (10 $\mu \mathrm{L}$ PCR product was loaded per well and $7 \mu \mathrm{L}$ of $100 \mathrm{bp}$ DNA ladder). The Illumina sequence data reported here have been deposited in the European Nucleotide Archive (ENA) (https://www.ebi.ac.uk/ena/submit/sra/) under study accession number PRJEB23191.

\subsection{Specific Geobacter/Desulfuromonas Primer Sets}

To differentiate between the two common dominant anode respiring bacterial genera present in all experiments (Geobacter and Desulfuromonas), using a technique independent of amplicon sequencing, several specific PCR primer pairs, previously designed to target these bacterial groups, were tested (Table 1). 
Table 1. List of primer sets used for detecting specific anode respiring bacteria.

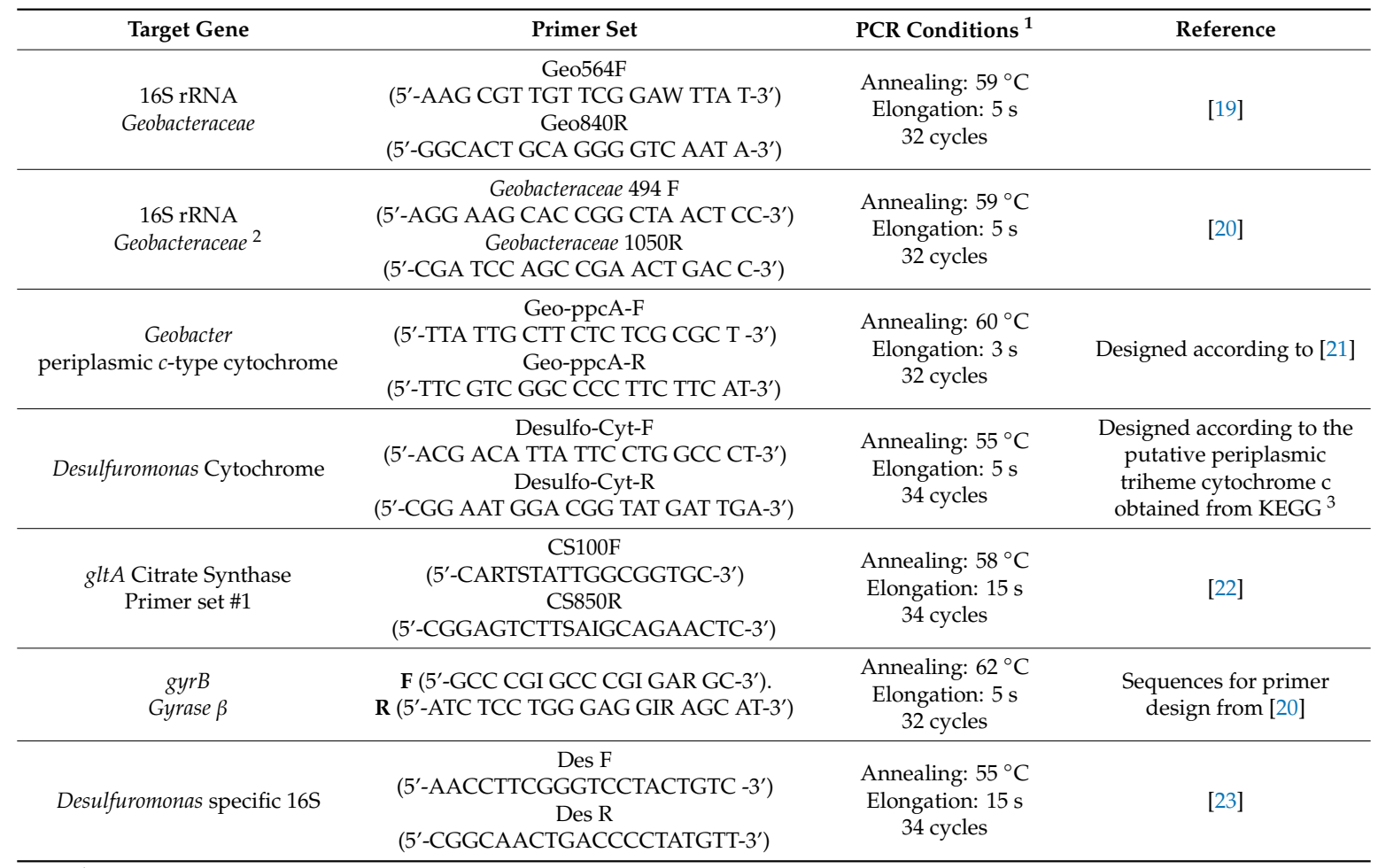

${ }^{1}$ All PCR reaction programs had the basic steps, including the following: initialization step, $95{ }^{\circ} \mathrm{C}$ for $3 \mathrm{~min}$; denaturation step, $95{ }^{\circ} \mathrm{C}$ for $15 \mathrm{~s}$; annealing step, temperature for each primer set is indicated in the table; elongation step, $72{ }^{\circ} \mathrm{C}$, the time is indicated for each primer set is indicated in the table (5-15 s elongation time per $1 \mathrm{k} \mathrm{bp}$ ). Repeating the processes of denaturation, annealing, and elongation (the \# of repeat times is indicated in the table). ${ }^{2}$ This primer set was stated to be specific to Desulfuromonas-like, strains [24]. ${ }^{3}$ http://www.genome.jp/dbget-bin/www_bget?des:DSOUD_0815.

An increasing annealing temperature gradient was applied for each control sample, ranging from 56 to $64{ }^{\circ} \mathrm{C}$. The highest temperature showing a clear and single band was chosen as the final annealing temperature for the specific primer set employed. The three control samples used were pure DNA purchased from DSMZ (https://www.dsmz.de/home.html), i.e., Desulfuromonas acetexigens, DSM 1397 and Geobacter lovleyi, DSM 17278.

All PCR reactions were conducted in a laboratory PCR machine S1000TM Thermal Cycler, Bio-Rad using the KAPA2G Fast Multiplex Mix, Kapa Biosystems Ltd.

\subsection{Electroactive Consortium Enrichment on Agar Plates}

A single anode sample (one $0.2 \mathrm{~cm}$ depth disk) was placed into a $2 \mathrm{~mL}$ Eppendorf filled with BCM medium and 4-5 sterilized glass beads. Sample was vortexed at half of maximal speed, on the flat-bed adaptor (Vortex Genie2, Scientific industries, Inc., Suffolk County, NY, USA), for $2.5 \mathrm{~min}$. At this point, anode "dust" was observed, caused by the detachment of anode-attached cells. However, most of the anode remained whole. Then, $100 \mu \mathrm{L}$ of each vortexed-anode sample were plated (using a plastic Dregalski stick) on x10 BCM sodium fumarate plates (Supplementary Table S1). Plates were kept in an anaerobic jar at room temperature in the dark under anaerobic conditions using anaerobic sachets.

\subsection{Statistical Analysis}

Startup times and maximal current density (or voltage) between closed-circuit MFCs were compared with the Mann-Whitney nonparametric statistical test (using GraphPad Prism software version 5.03). Statistical significance was inferred when $p<0.05$. 


\section{Results}

We observed, throughout three different experiments conducted between 2015 and 2016, considerable variation in the development of voltage production following the inoculation process of MFCs. The lag phase is defined here as the time until the MFC reaches $30 \mathrm{mV}$. This value was chosen arbitrarily as a value that was higher than base-line voltage, indicating that the biofilm was starting to acclimate to the anode, yet was still in an initial stage of development. Startup time was defined as the time to reach steady-state voltage production, i.e., the time to reach the maximum voltage that a particular anodic biofilm was able to produce under specific given conditions. The startup phase of MFCs from all three experiments $(\mathrm{N}=16)$, therefore, could be classified into either "efficient" (shorter than 25 days) or "non-efficient" (Figure 1). This heterogeneity in startup time efficiency necessitates specific biomarkers for identifying dominant key species involved in forming an efficient anodic biofilm at early stages.

\section{- Efficient MFC - Non-efficient MFC}

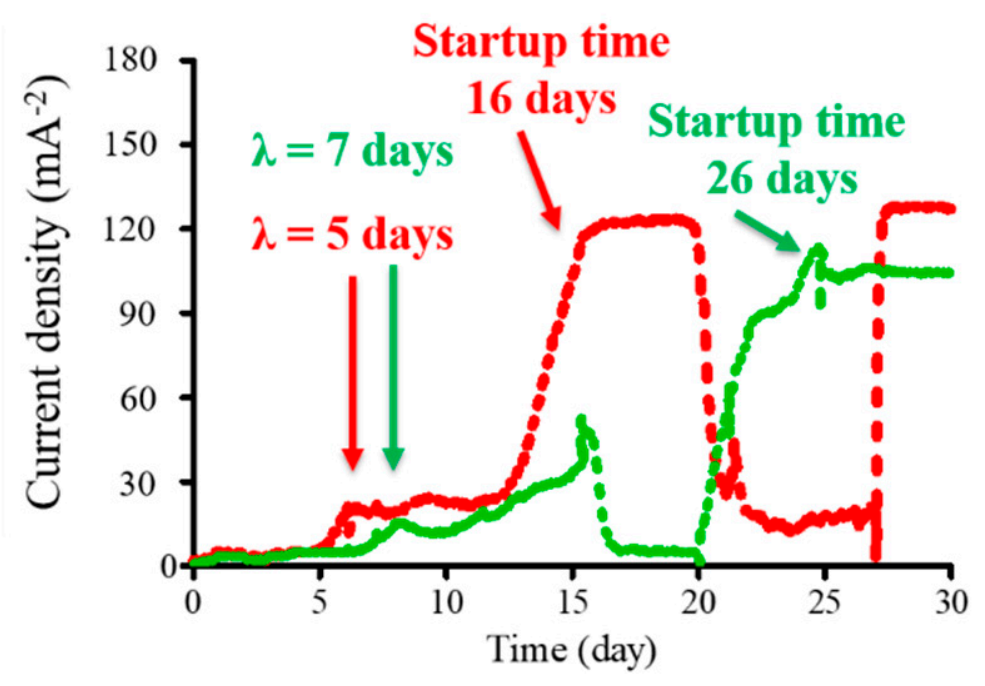

Figure 1. Current density production growth curve of two representative microbial fuel cells (MFCs), efficient and non-efficient. $\lambda$ is lag phase length, the time it took to reach $30 \mathrm{mV}$.

Recently, we showed that while all anodic biofilms were composed of Desulfuromonadaceae, MFCs differed in startup times [17]. Although Desulfuromonadaceae has been found to be an important member of the anodic biofilm, very little is currently known regarding the molecular activity within MFC systems [25]. In this study, our main goal was to investigate strain level dynamics within the Desulformondanceae arising in the anodic biofilm. The Geobacteraceae family are thought to be the typical and most predominant electroactive bacteria in MFC systems, thus, this taxonomic group has been widely studied and probes targeting it have been developed [20-22,26,27]. Because Geobacteraceae and Desulfuromonadaceae are phylogenetically closely related [28], we tested several semi-specific published primer sets on different DNA samples in an effort to differentiate between them by PCR without resorting to sequencing (Table 1 and Supplementary Figure S1). Only one PCR primer set, hereby referred to as Desulfuromonas dechlorinator-targeted primers [23], was indeed specific to Desulfuromonas (Figure 2) and showed a clear differentiation between Desulfuromonadaceae and Geobacteraceae.

Figure 2 shows clearly that not all samples that show the presence of the Desulfuromonadaceae family by the amplicon sequencing analysis, have a positive PCR product with the specific 16S-Desulfuromonadaceae primer set. For example, according to amplicon sequencing results, $21 \%$ of Sample 3 was composed of the Desulfuromonadaceae family, however, it had no product from the 16S-Desulfuromonadaceae primer set reaction. Notably, this was not due to the lower relative abundance of Sample 3, as other samples with a lower Desulfuromonadaceae relative abundance did produce a PCR 
product (Table 2). Interestingly, Samples 1 and 3 were anodic biofilm DNA samples taken from an efficient and non-efficient MFC, respectively.

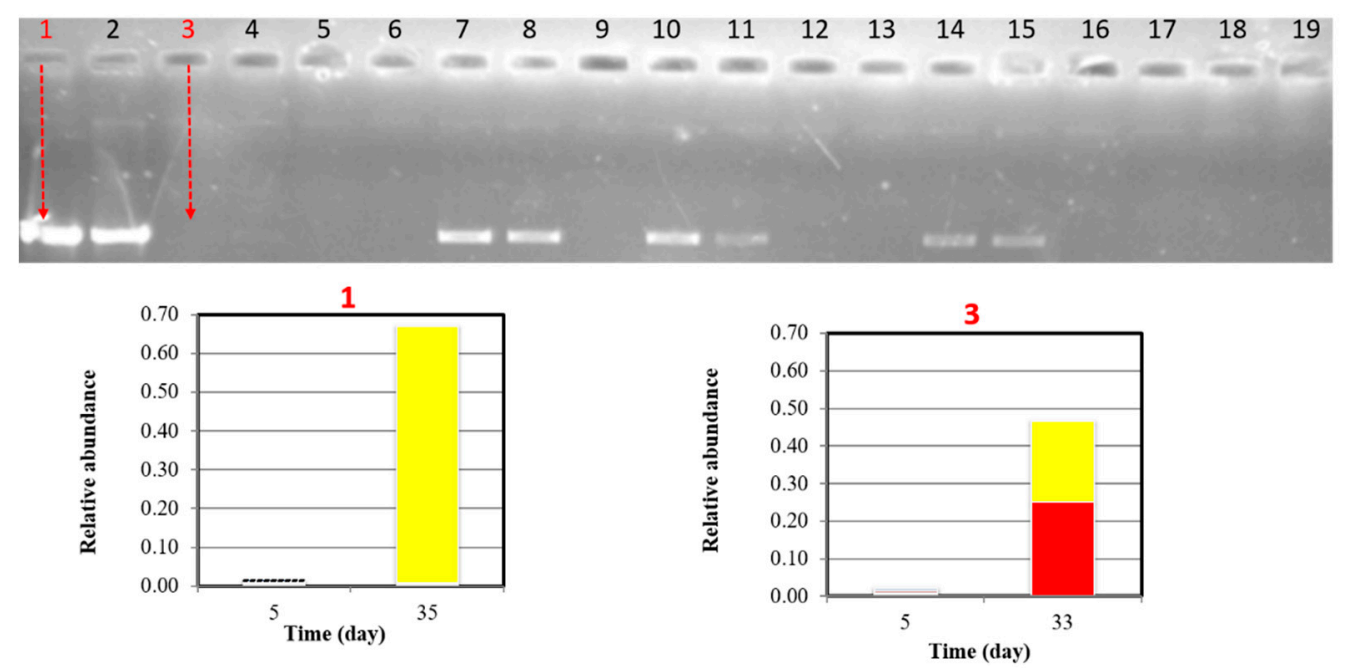

Figure 2. PCR products obtained with the specific 16S-Desulfuromonadaceae primers. Samples 1-19 were tested as representative samples for the presence and absence of Desulfuromonadaceae and Geabacteraceae bacterial families, as indicated in Table 2. The anodic composition of Samples 1 and 3 are shown as an example illustrating the association of community composition to a positive and negative PCR product of this primer set, respectively.

Table 2. The samples used for testing the different primer sets for their specificity to the Desulfuromonadaceae and Geabacteraceae groups with their relative abundance according to amplicon sequencing results. * Indicates the sample had a positive PCR product for the specific 16S-Desulfuromonadaceae primer set [29].

\begin{tabular}{ccc}
\hline Sample ID & $\begin{array}{c}\text { Geabacteraceae } \\
\text { Relative Abundance According } \\
\text { to Amplicon Sequencing }\end{array}$ & $\begin{array}{c}\text { Desulfuromonadaceae } \\
\text { Relative Abundance According } \\
\text { to Amplicon Sequencing }\end{array}$ \\
\hline 1 & 0.007 & $0.661^{*}$ \\
2 & 0.019 & $0.483^{*}$ \\
3 & 0.248 & 0.216 \\
4 & 0.207 & 0.254 \\
5 & 0.368 & 0.051 \\
6 & 0.201 & 0.088 \\
7 & 0.081 & $0.179^{*}$ \\
8 & 0.083 & $0.025^{*}$ \\
9 & 0.011 & 0.091 \\
10 & 0.019 & $0.076^{*}$ \\
11 & 0.035 & $0.015^{*}$ \\
13 & 0.024 & 0.025 \\
14 & 0.014 & 0.011 \\
15 & 0.005 & $0.020^{*}$ \\
16 & 0.006 & $0.005^{*}$ \\
17 & 0.003 & 0.001 \\
18 & 0.001 & 0.004 \\
19 & 0 & 0 \\
\hline
\end{tabular}

\footnotetext{
* Relative abundance of Geabacteraceae/Desulfuromonadaceae is according to 16S-rDNA amplicon sequencing, representing relative abundance of each operational taxonomic unit (OTU) from the entire community in each sample.
}

Remarkably, all the samples that did yield a PCR product with the Desulfuromonas dechlorinator-targeted primers originated in efficient MFCs, while samples from non-efficient MFCs 
did not yield a PCR product (Figure 3). Thus, it appears that a specific Desulfuromonadaceae strain was associated with efficient MFCs. Although the specific strain detected by the Desulfuromonas dechlorinator-targeted primers was not detectable during the startup phase in non-efficient MFCs, it could be enriched at later stages of operation of these MFCs. Importantly, in our experiments, all MFCs displayed similar electrochemical behavior at later stages (Supplementary Figure S2). Accordingly, even MFCs that had a non-efficient startup phase yielded a PCR product with the Desulfuromonas dechlorinator-targeted primers at later stages of the MFC operation (Figure 4).

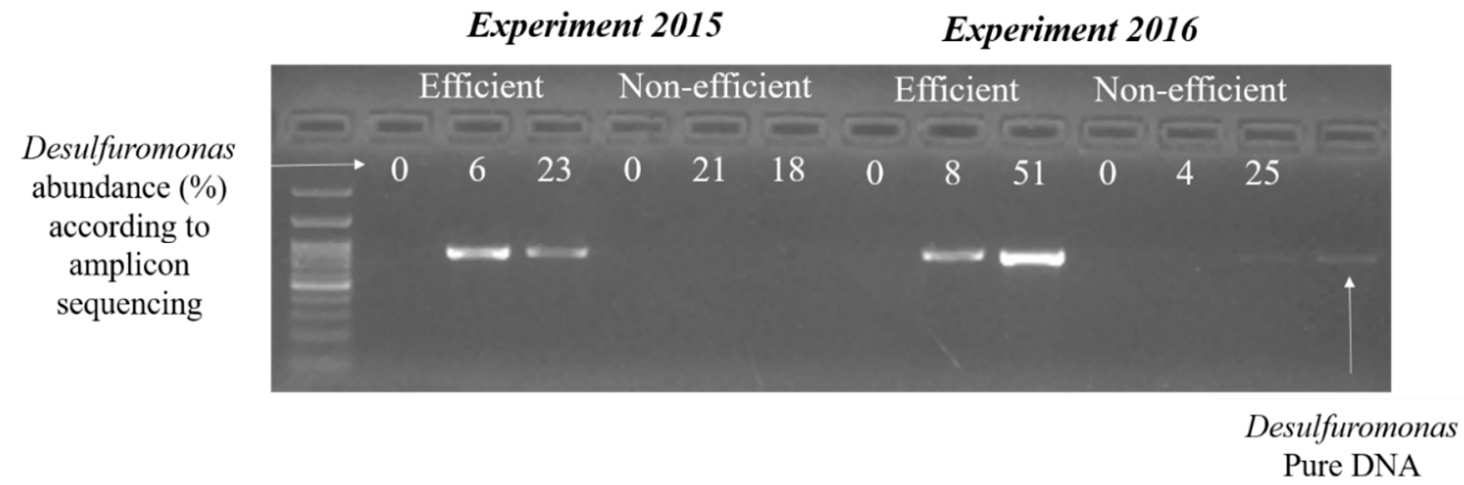

Figure 3. PCR products obtained with the specific Desulfuromonas dechlorinator-targeted primers of representative MFCs as indicated on the gel for experiments 2015 and 2016. Desulfuromonas pure DNA was purchased from DSMZ for Desulfuromonas acetexigens, DSM 1397 and performed as a positive control. First lane from the left is a $100 \mathrm{bp}$ size ladder.

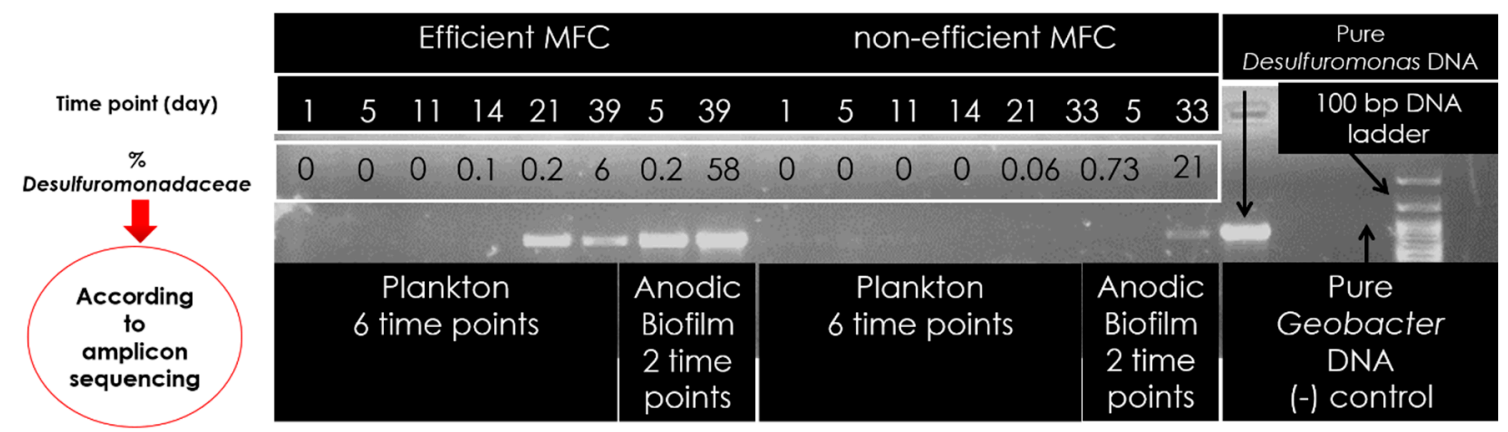

Figure 4. PCR products obtained with the specific 16S-Desulfuromonadaceae primers for efficient and non-efficient MFCs. Relative abundance of Desulfuromonadaceae according to amplicon sequencing is shown. Last lane from the left is a $100 \mathrm{bp}$ size ladder.

Thus, the emergence of the "efficient" Desulfomonas strain is characteristic of a stable, voltage-producing biofilm. Notably, this "efficient" Desulformonas strain could be identified by PCR even in the planktonic fraction (as shown in Figure 4), consequently, allowing on-line monitoring without the need to sample and disrupt the anode.

\section{Direct Application of an Anode Enrichment Consortium Reduces Significantly Startup Times}

Because it appeared that certain Desulformonas strains were associated with efficient MFC startup, next, we attempted to enrich those strains from a working MFC and directly apply them to new anodes (experiment 2016-E). An anode sample was taken from an efficient MFC that had been running for forty days. This sample was placed directly on an agar plate containing BCM as the basic medium with acetate as a single electron donor source, and fumarate as the electron acceptor. Once bacterial colonies started to grow, five suspected colonies were tested using the Desulfuromonas dechlorinator-targeted primers (Supplementary Figure S1d). 
Phylogenetic analysis of this colony revealed that additional bacterial species were present (Supplementary Figure S3), therefore, we referred to it as a highly enriched electroactive consortium. Then, the colonies were applied on clean anodes by spreading the colony onto the anode surface, and then these anodes were inoculated inside MFCs [30]. Figure 5 compares the lag time and time to reach steady-state current density for all experimental sets conducted in this study. From these experiments, it is evident that lag time was significantly reduced when directly applying a highly enriched electroactive consortium. MFCs inoculated with only wastewater (i.e., no enrichment of the anode, experiments 2015, 2016, and 2016-2), had a mean lag time of five days and a mean startup time to reach stable current production of 16 days. These times are significantly higher than those obtained by MFCs that were pretreated with an electroactive consortium (lag times of $6 \mathrm{~h}$, and startup time to reach steady-state voltage of 2.9 days). In contrast to the reduced startup times, no difference was observed with regards to the maximal current density obtained by the different experimental sets (Supplementary Figure S4).

a

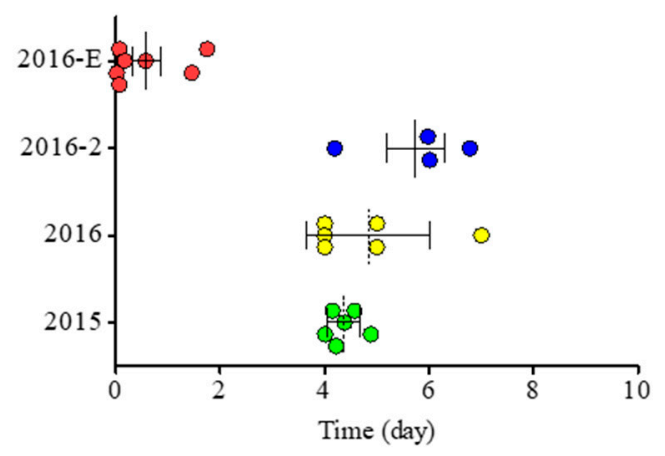

$\mathrm{b}$

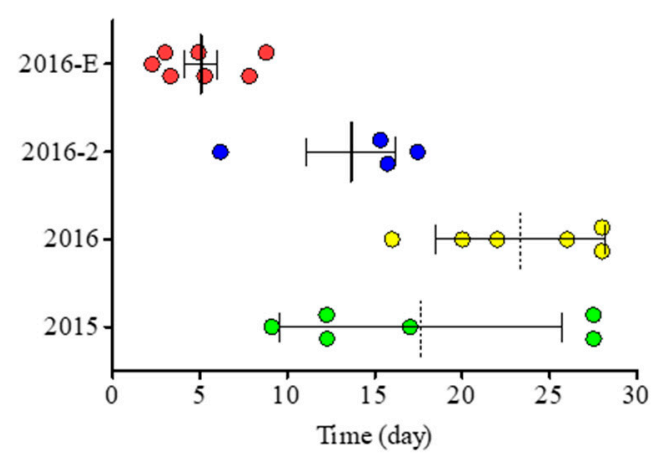

Figure 5. Summary of (a) lag time and (b) startup time for all experiments in this work, i.e., 2015, 2016, 2016-S, 2016-2, and 2016-E.

\section{Discussion}

During the course of our experiments, we observed that replicate MFCs often vary greatly in their startup times, probably due to stochastic effects, for example, the rare electroactive organisms in the inoculum may be strongly affected by random events [31,32]. This variability allowed us to investigate microbial factors affecting startup times. Although Geobacteraceae species are well known as the prime and most dominant anode respiring bacteria in MFCs [33], in our system Desulfuromonadaceae were much more abundant in the anodic biofilm.

A specific primer set was initially designed by Löffler et al. [23] to detect the acetate-oxidizing, PCE-dechlorinating Desulfuromonas group in contaminated soils. This primer set was tested on MFC samples in our study, taken during the startup phase. Interestingly, an amplification product could be associated with samples from efficient startup MFCs only. Nevertheless, this Desulformonas taxon was eventually detected in all MFCs (also non-efficient), once a stable electroactive biofilm had evolved (Figure 4). Thus, it appears to be an important member of electroactive biofilms. Of note, this specific Desulformonas taxon could also be identified in planktonic samples (Figure 4) in a simple PCR assay, thereby showing potential for MFC monitoring in real-world situations.

The Desulfuromonadaceae taxa, observed in our study, were found to be closely related to Desulfuromonas acetexigens, an acetate-oxidizing, sulfur-reducing bacterium isolated from freshwater habitats [34]. The Desulfuromonas dechlorinator primer set has previously been shown to be specific towards D. acetexigens, D. chloroethenica, and Desulfuromonas sp. strain BB1 but other Desulfuromonas strains tested, including D. thiophila, D. palmitatis, D. acetoxidans, D. succinoxidans, Pelobacter acetylenicus, and Geobacter metallireducens, did not result in amplification [23]. Additionally, the Geobacteraceae 
taxa, observed in our study, were closely related to Geobacter lovleyi SZ, a novel Geobacter species, capable of coupling the oxidation of acetate and $\mathrm{H}_{2}$ to the reduction of a variety of electron acceptors, including tetrachloroethene, trichloroethene, nitrate, and uranium, a property that has previously been demonstrated mostly for members of the Desulfuromonas cluster [35].

In spite of this similarity in metabolic capabilities of Geobacter lovleyi SZ and the Desulfuromonas strains in our reactors, and the fact both were abundant in the anodic biofilm, the former was not associated with an amplification product (Supplementary Figure S1), showing that the primer set was specific only for known Desulfuromonas PCE dechlorinators, as shown by [23].

Application of an anode enrichment consortium reduces startup times significantly. While several studies have reported Desulfuromonas species to be abundant in microbial communities colonizing the anode [24,36,37], inoculation of MFCs with pure cultures of these bacteria has not been tested to date [38]. As proof-of-concept for such an approach, we have isolated a consortium of Desuformonas-enriched bacteria (Supplementary Figure S3) from an active anodic biofilm of an efficient operating MFC. The direct application of such an enriched consortium to a new sterile anode dramatically reduced lag time, from an average of five days to several hours (Figure 5). Nevertheless, stable voltage outputs that were obtained by the enrichment-treated MFCs were similar to the other treatment group. These results are contradictory with those previously reported by Kim et al. [39], where directly applying a biofilm scraped from an active anode to a new one, yielded no significant difference in the lag phase as compared with unacclimated MFCs inoculated with sludge alone. Curiously, in that study, the voltage generated was considerably higher in the MFCs where bacteria were directly applied as compared with the control, unacclimated MFCs. Since the microbial community was not characterized in that study, the differences between their results and ours remain unclear. However, the data that we present show that the substantially reduced startup times were achieved after applying an electroactive consortium highly enriched with the specific Desulfuromonas strain associated with efficient MFCs, and directly detected by the Desulfuromonas dechlorinator-targeted primer set. Taken together these findings imply that one can apply and monitor, in real time, consortia enriched in reproducibly electroactive bacteria, bringing us one step closer to feasible MFC wastewater treatment solutions.

\section{Conclusions}

Major challenges in scaling up MFCs are to reduce the time it takes to build an efficient electroactive biofilm on an anode and to better understand and control the biological system. Usually, once the inoculation of the system has started, a waiting period of at least three weeks is required prior to achieving a stable and active biofilm. Since biofilm development is based on the microbial community composition of the inoculum source, this is an important criterion to a successful active biofilm. Therefore, in this work, a real-time monitoring approach of the planktonic phase was proposed as a tool for predicting, in advance, when and how the system would perform. Interestingly, the phylogenetic classification of the two main $\delta$-Proteobacteria players was Geobacter lovleyi SZ and Desulfuromonas acetexigens; both have been previously reported to be highly abundant in contaminated soils capable of utilizing PCE and TCE (Trichloroethylene) as metabolic electron acceptors. A specific 16S rRNA gene PCR primer set that was designed for detecting the acetate-oxidizing, PCE-dechlorinating Desulfuromonas group was tested on the anodic biofilm and planktonic samples in this study. Surprisingly, a positive PCR product was associated with efficient-MFCs samples. Nevertheless, an MFC that was considered non-efficient at early phases of operation and had no PCR product could yield a positive amplification at later stages, inferring that different Desulfuromonas strains gradually acclimate the anodic biofilms. Finally, a novel electroactive species, closely related to Desulfuromonadaceae, was successfully enriched from a working anodic biofilm. Direct application of the enrichment to an MFC anode surface showed a rapid increase in current density relative to MFCs with clean anode surfaces.

Supplementary Materials: The following are available online at http://www.mdpi.com/2076-3417/10/23/8570/s1, Figure S1: PCR products obtained with different specific primers sets targeted for Geobacter and Desulfuromonas 
under temperature gradient conditions, Figure S2: Electrochemical performance of the six closed-circuit MFC reactors in each experiment, Figure S3: Composition of the enrichment consortium, used for the direct application experiment based on 16S-amplicon sequencing, Figure S4: Steady-state current density obtained for each experiment set, Table S1: Components added to 0.5 L DDW with agar for preparation of petri plates.

Author Contributions: Conceptualization, K.Y.-G., U.G. and L.R.; Formal analysis, K.Y.-G.; Investigation, K.Y.-G.; Methodology, K.Y.-G. and L.R.; Resources, J.R.; Supervision, J.R. and U.G.; Writing-original draft, K.Y.-G.; Writing-review and editing, L.R. and U.G. All authors have read and agreed to the published version of the manuscript.

Funding: This research was funded by Israel's Ministry of Environmental Protection (MOEP), grant number 132-4-2.

Acknowledgments: The authors are grateful for the Tel-Aviv University Smaller-Winnikow Fellowship. In addition, we would like to personally thank Klimentiy Levkov for helping with the MFCs setup.

Conflicts of Interest: The authors declare no conflict of interest. The funders had no role in the design of the study; in the collection, analyses, or interpretation of data; in the writing of the manuscript, or in the decision to publish the results.

\section{References}

1. Drendel, G.; Mathews, E.R.; Semenec, L.; Franks, A.E. Microbial fuel cells, related technologies, and their applications. Appl. Sci. 2018, 8, 2384. [CrossRef]

2. Li, W.-W.; Yu, H.-Q. Stimulating sediment bioremediation with benthic microbial fuel cells. Biotechnol. Adv. 2015, 33, 1-12. [CrossRef] [PubMed]

3. Friedman, E.; Miller, K.; Lipson, D.; Angenent, L. Potentiostatically Poised Electrodes Mimic Iron Oxide and Interact with Soil Microbial Communities to Alter the Biogeochemistry of Arctic Peat Soils. Minerals 2013, 3, 318-336. [CrossRef]

4. Koch, C.; Harnisch, F. Is there a Specific Ecological Niche for Electroactive Microorganisms? ChemElectroChem 2016, 3, 1282-1295. [CrossRef]

5. Richter, K.; Schicklberger, M.; Gescher, J. Dissimilatory Reduction of Extracellular Electron Acceptors in Anaerobic Respiration. Appl. Environ. Microbiol. 2012, 78, 913-921. [CrossRef]

6. Pfennig, N.; Biebl, H. Desulfuromonas acetoxidans gen. nov. and sp. nov., a new anaerobic, sulfur-reducing, acetate-oxidizing bacterium. Arch Microbiol. 1976, 110, 3-12. [CrossRef]

7. Roden, E.E.; Lovley, D.R. Dissimilatory Fe (III) Reduction by the Marine Microorganism Desulfuromonas acetoxidans Dissimilatory Fe (III) Reduction by the Marine Microorganism Desulfuromonas acetoxidans. Appl. Environ. Microbiol. 1993, 59, 734-742. [CrossRef]

8. Butler, J.E.; Young, N.D.; Lovley, D.R. Evolution from a respiratory ancestor to fill syntrophic and fermentative niches: Comparative genomics of six Geobacteraceae species. BMC Genomics 2009, 10, 103. [CrossRef]

9. Beecroft, N.J.; Zhao, F.; Varcoe, J.R.; Slade, R.C.T.; Thumser, A.E.; Avignone-Rossa, C. Dynamic changes in the microbial community composition in microbial fuel cells fed with sucrose. Appl. Microbiol. Biotechnol. 2012, 93, 423-437. [CrossRef]

10. Chae, K.-J.; Choi, M.-J.; Lee, J.-W.; Kim, K.-Y.; Kim, I.S. Effect of different substrates on the performance, bacterial diversity, and bacterial viability in microbial fuel cells. Bioresour. Technol. 2009, 100, 3518-3525. [CrossRef]

11. Commault, A.S.; Barrière, F.; Lapinsonnière, L.; Lear, G.; Bouvier, S.; Weld, R.J. Influence of inoculum and anode surface properties on the selection of Geobacter-dominated biofilms. Bioresour. Technol. 2015, 195, 265-272. [CrossRef] [PubMed]

12. Cui, M.-H.; Cui, D.; Gao, L.; Cheng, H.-Y.; Wang, A.-J. Analysis of electrode microbial communities in an up-flow bioelectrochemical system treating azo dye wastewater. Electrochim. Acta 2016, 220, $252-257$. [CrossRef]

13. Hodgson, D.M.; Smith, A.; Dahale, S.; Stratford, J.P.; Li, J.V.; Grüning, A.; Bushell, M.E.; Marchesi, J.R.; Avignone Rossa, C. Segregation of the anodic microbial communities in a microbial fuel cell cascade. Front. Microbiol. 2016, 7, 699. [CrossRef]

14. Lee, Y.-Y.; Kim, T.G.; Cho, K. Effects of proton exchange membrane on the performance and microbial community composition of air-cathode microbial fuel cells. J. Biotechnol. 2015, 211, 130-137. [CrossRef] [PubMed] 
15. Paitier, A.; Godain, A.; Lyon, D.; Haddour, N.; Vogel, T.M.; Monier, J.-M. Microbial fuel cell anodic microbial population dynamics during MFC start-up. Biosens. Bioelectron. 2017, 92, 357-363. [CrossRef]

16. Ren, Z.; Yan, H.; Wang, W.; Mench, M.M.; Regan, J.M. Characterization of microbial fuel cells at microbially and electrochemically meaningful time scales. Environ. Sci. Technol. 2011, 45, 2435-2441. [CrossRef]

17. Yanuka-Golub, K.; Reshef, L.; Rishpon, J.; Gophna, U. Community structure dynamics during startup in microbial fuel cells-The effect of phosphate concentrations. Bioresour. Technol. 2016, 212, 151-159. [CrossRef]

18. Rabaey, K.; Ossieur, W.; Verhaege, M.; Verstraete, W. Continuous microbial fuel cells convert carbohydratesto electricity. Water Sci. Technol. 2005, 52, 515-523. [CrossRef]

19. Cummings, D.E.; Snoeyenbos-West, O.L.; Newby, D.T.; Niggemyer, A.M.; Lovley, D.R.; Achenbach, L.A.; Rosenzweig, R.F. Diversity of geobacteraceae species inhabiting metal-polluted freshwater lake sediments ascertained by $16 \mathrm{~S}$ rDNA analyses. Microb. Ecol. 2003, 46, 257-269. [CrossRef]

20. Holmes, D.E.; Nevin, K.P.; Lovley, D.R. Comparison of $16 \mathrm{~S}$ rRNA, nifD, recA, gyrB, rpoB and fusA genes within the family Geobacteraceae fam. nov. Int. J. Syst. Evol. Microbiol. 2004, 54, 1591-1599. [CrossRef]

21. Lloyd, J.R.; Leang, C.; Hodges Myerson, A.L.; Coppi, M.V.; Cuifo, S.; Methe, B.; Sandler, S.J.; Lovley, D.R. Biochemical and genetic characterization of PpcA, a periplasmic c-type cytochrome in Geobacter sulfurreducens. Biochem. J. 2003, 369, 153-161. [CrossRef] [PubMed]

22. Holmes, D.E.; Nevin, K.P.; O’Neil, R.A.; Ward, J.E.; Adams, L.A.; Woodard, T.L.; Vrionis, H.A.; Lovley, D.R. Potential for quantifying expression of the Geobacteraceae citrate synthase gene to assess the activity of Geobacteraceae in the subsurface and on current-harvesting electrodes. Appl. Environ. Microbiol. 2005, 71, 6870-6877. [CrossRef] [PubMed]

23. Löffler, F.E.; Sun, Q.; Li, J.; Tiedje, J.M. $16 \mathrm{~S}$ rRNA gene-based detection of tetrachloroethene-dechlorinating Desulfuromonas and Dehalococcoides species. Appl. Environ. Microbiol. 2000, 66, 1369-1374. [CrossRef] [PubMed]

24. Bond, D.R.; Holmes, D.E.; Tender, L.M.; Lovley, D.R. Electrode-Reducing Microorganisms That Harvest Energy from Marine Sediments. Science 2002, 295, 483-485. [CrossRef]

25. Heidrich, E.S.; Curtis, T.P.; Woodcock, S.; Dolfing, J. Quantification of effective exoelectrogens by most probable number (MPN) in a microbial fuel cell. Bioresour. Technol. 2016, 218, 27-30. [CrossRef]

26. Holmes, D.E.; Finneran, K.T.; O'Neil, R.A.; Lovley, D.R. Enrichment of members of the family Geobacteraceae associated with stimulation of dissimilatory metal reduction in uranium-contaminated aquifer sediments. Appl. Environ. Microbiol. 2002, 68, 2300-2306. [CrossRef]

27. Holmes, D.E.; Chaudhuri, S.K.; Nevin, K.P.; Mehta, T.; Methé, B.A.; Liu, A.; Ward, J.E.; Woodard, T.L.; Webster, J.; Lovley, D.R. Microarray and genetic analysis of electron transfer to electrodes in Geobacter sulfurreducens. Environ. Microbiol. 2006, 8, 1805-1815. [CrossRef]

28. Lonergan, D.J.; Jenter, H.L.; Coates, J.D.; Phillips, E.J.; Schmidt, T.M.; Lovley, D.R. Phylogenetic analysis of dissimilatory Fe(III)-reducing bacteria. J. Bacteriol. 1996, 178, 2402-2408. [CrossRef]

29. Daprato, R.C.; Löffler, F.E.; Hughes, J.B. Comparative analysis of three tetrachloroethene to ethene halorespiring consortia suggests functional redundancy. Environ. Sci. Technol. 2007, 41, 2261-2269. [CrossRef]

30. Yanuka-Golub, K.; Dubinsky, V.; Korenblum, E.; Reshef, L.; Ofek-Lalzar, M.; Rishpon, J.; Gophna, U. Anode surface bioaugmentation enhances deterministic biofilm assembly in microbial fuel cells. bioRxiv 2020. [CrossRef]

31. Zhang, Z.; Deng, Y.; Feng, K.; Cai, W.; Li, S.; Yin, H.; Xu, M.; Ning, D.; Qu, Y. Deterministic Assembly and Diversity Gradient Altered the Biofilm Community Performances of Bioreactors. Environ. Sci. Technol. 2019, 53, 1315-1324. [CrossRef] [PubMed]

32. Zhou, J.; Liu, W.; Deng, Y.; Jiang, Y.-H.; Xue, K.; He, Z.; Van Nostrand, J.D.; Wu, L.; Yang, Y.; Wang, A. Stochastic assembly leads to alternative communities with distinct functions in a bioreactor microbial community. MBio 2013, 4, e00584-12. [CrossRef] [PubMed]

33. Lovley, D.R. Electromicrobiology. Annu. Rev. Microbiol. 2012, 66, 391-409. [CrossRef] [PubMed]

34. Finster, K.; Bak, F.; Pfennig, N. Desulfuromonas acetexigens sp. nov., a dissimilatory sulfur-reducing eubacterium from anoxic freshwater sediments. Arch Microbiol. 1994, 161, 328-332. [CrossRef]

35. Sung, Y.; Fletcher, K.E.; Ritalahti, K.M.; Apkarian, R.P.; Ramos-Hernández, N.; Sanford, R.A.; Mesbah, N.M.; Löffler, F.E. Geobacter lovleyi sp. nov. strain SZ, a novel metal-reducing and tetrachloroethene-dechlorinating bacterium. Appl. Environ. Microbiol. 2006, 72, 2775-2782. [CrossRef] [PubMed] 
36. Lovley, D.R. Microbial fuel cells: Novel microbial physiologies and engineering approaches. Curr. Opin. Biotechnol. 2006, 17, 327-332. [CrossRef]

37. Pierra, M.; Carmona-Martínez, A.A.; Trably, E.; Godon, J.-J.; Bernet, N. Microbial characterization of anode-respiring bacteria within biofilms developed from cultures previously enriched in dissimilatory metal-reducing bacteria. Bioresour. Technol. 2015, 195, 283-287. [CrossRef]

38. Cavaleiro, A.J.; Abreu, A.A.; Sousa, D.Z.; Pereira, M.A.; Alves, M.M. The role of marine anaerobic Bacteria and Archaea in bioenergy production. In Management of Microbial Resources in the Environment; Springer: Berlin/Heidelberg, Germany, 2013; pp. 445-469.

39. Kim, J.R.; Min, B.; Logan, B.E. Evaluation of procedures to acclimate a microbial fuel cell for electricity production. Appl. Microbiol. Biotechnol. 2005, 68, 23-30. [CrossRef]

Publisher's Note: MDPI stays neutral with regard to jurisdictional claims in published maps and institutional affiliations.

(C) 2020 by the authors. Licensee MDPI, Basel, Switzerland. This article is an open access article distributed under the terms and conditions of the Creative Commons Attribution (CC BY) license (http://creativecommons.org/licenses/by/4.0/). 